\section{VITAL STATISTIOS.}

HEALTH OF RNGLISH TOWNS,

IN twenty-eight of the largest English towns 5799 births and 3252 deaths were registered during the week ending June 18th. The annual rate of mortality in these towns, which had been $20^{\circ} 4,19 \cdot 5$, and 18.9 per 1000 in the preceding three weeks, further declined last week to 18.4 , and was lower than in any preceding week of this year. During the first eleven weeks of the current quarter the death-rate in these towns averaged 20.1 per 1000 , and was 1.5 below the mean rate in the corresponding periods of the ten years 1877-86. The lowest rates in these towns last week were 12.2 in Derby, 13.4 in Birmingham, 13.8 in Halifax, and 14.1 in Norwich. The rates in the other towns ranged upwards to 24.3 in Huddersfield, $25^{\circ} 0$ in Blackburn, 26.2 in Newcastle-on-Tyne, and 28.5 in Manchester. The deaths referred to the principal zymotic diseases in the twentyeight towns, which had declined in the preceding four weeks from 532 to 489 , were last week 501 ; they included 226 from measles, 132 from whooping-cough, 41 from scarlet fever, 49 from diarrhœa, 26 from diphtheria, 27 from "fever" (principally enteric), and not one from small-pox. No death from any of these zymotic diseases was registered during the week in Wolverhampton; while they caused the greatest mortality in Brighton, Blackburn, Birkenhead, and Manchester. The highest death-rates from measles occurred in Sheffield, Oldham, Salford, Norwich, Brighton, Manchester, and Birkenhead ; from whooping-cough in Plymouth, Bradford, and Nottingham; and from scarlet fever in Blackburn. The 26 deaths from diphtheria in the twenty-eight towns included 16 in London and 2 in Huddersfield. Small-pox caused no death either in Greater London or in any of the twenty-seven large provincial towns. Only two cases of small-pox were under treatment on Saturday last in the metropolitan hospitals receiving cases of this disease; one new case was admitted to these hospitals during the week. The deaths referred to diseases of the respiratory organs in London, which had been 333,264 , and 259 in the preceding three weeks, further declined last week to 213 , and were 23 below the corrected weekly average. The causes of 78 , or 2.4 per cent, of the deaths in the twenty-eight towns last week were not certified either by a registered medical practitioner or by a coroner. All the causes of death were duly certified in Birmingham, Bristol, Sunderland, Nottingham, and in three other smaller towns. The largest proportions of uncertified deaths were registered in Huddersfield, Halifax, Salford, and Sheffield.

\section{HEALTH OF SCOTCH TOWNS.}

The annual rate of mortality in the eight Scotch towns, which had been 19.8 and 21.9 per 1000 in the preceding two weeks, declined again to 19.3 in the week ending June 18th; this rate exceeded, bowever, by 0.9 the mean rate during the same week in the twenty-eight large English towns. The rates in the Scotch towns last week ranged from 9.7 and 12.4 in Perth and Aberdeen, to 22.2 in Paisley and 230 in Dundee. The 483 deaths in the eight towns last week showed a decline of 63 from the number in the previous week, and included 48 which were referred to whooping-cough, 13 to measles, 10 to scarlet fever, 10 to diarrhoea, 5 to "fever" (typhus, enteric, or simple), 4 to diphtheria, and not one to small-pox; in all, 90 deaths resulted from these principal zymotic diseases, against 50 and 76 in the preceding two weeks. These 90 deaths were equal to an annual rate of 36 per 1000 , which was 0.7 above the mean rate from the same diseases in the twentyeight English towns. The fatal cases of whooping-cough, which had been 32 and 35 in the preceding two weeks, further rose last week to 48 , and included 16 in Glasgow, 14 in Dundee, 8 in Edinburgh, 4 in Greenock, and 4 in Leith. The deaths from measles and scarlet fever also exceeded the numbers in recent weeks; measles caused 11 deaths in Glasgow, and scarlet fever 6 in Glasgow and 3 in Dundee. The 10 deaths attributed to diarrbœa showed a decline of 2 from the number in the previous week, but exceeded those returned in the corresponding week of last year by 2 . Of the 5 deaths referred to "fever," 3 occurred in Glasgow. The deaths referred to acute diseases of the respiratory organs in the eight towns, which had been 102 and 109 in the preceding two weeks, declined last week to 76 , and was 17 below the number returned in the corresponding week of last year. The causes of 76 , or nearly 16 per cent., of the deaths registered in the eight towns during the week were not certified.

\section{HEALTH OF DUBITN.}

The rate of mortality in Dublin, which had been equal to 21.4 and 31.2 per 1000 in the preceding two weeks, declined again to $26^{\prime} 7$ in the week ending June 18th. During the first eleven weeks of the current quarter the death-rate in the city averaged 28.8 per 1000 , the mean rate during the same period being but 18.3 in London and 196 in Edinburgh. The 181 deaths in Dublin last week showed a decline of 30 from the number returned in the previous week; they included 18 which were referred to measles, 6 to scarlet fever, 5 to "fever" (typhus, enteric, or simple), 3 to whooping-cough, and not one either to small-pox, diphtheria, or diarrhoea. Thus the deaths resulting from these principal zymotic diseases, which had been 21 and 29 in the preceding two weeks, further rose last week to 32 , and exceeded the number in any previous week of this year; they were equal to an annual rate of 4.7 per 1000, the rates from the same diseases being 2.9 in London and 1.8 in Edinburgh. The fatal cases of measles, which had been 17,10 , and 18 in the preceding three weeks, were again 18 last week. The deaths from scarlet fever and "fever" showed an increase upon recent weekly numbers. The deaths both of infants and of elderly persons were fewer than those returned in the previous week. Two inquest cases and 2 deaths from violence were registered; and 57, or nearly a third, of the deaths occurred in public institutions. The causes of 24 , or more than 13 per cent., of the deaths registered during the week were not certified.

\section{(1)axespondente.}

$$
\text { "Audi alteram partem." }
$$

\section{“THE DOCTOR'S INOOME."}

\section{To the Editors of THE LANCET.}

SIRs,-Dr. Paget Thurstan is doubtless right in saying that his letters on the income of doctors have excited much interest. It is surely interesting, though not encouraging, to learn how poor we most of us are, and how unequal is the distribution of what wealth there is amongst us. What strikes me as of chiefest interest, however, in his letters and in other communications from other pens, is the tacit assumption that the hospital doctor is largely and mainly answer. able for all the woes and the poverty of his non-hospital brethren. And yet not a tacit assumption only, for after detailing the case of a patient who ultimately reached a hospital, where she was treated for nothing, and then died, her whole medical expenses throughout a long illness having amounted to five shillings, he says: "But the system which makes the hospital doctor breaks hundreds of his less fortunate brethren." If the hospital doctor is made in the country by his hospital connexion-made, that is, both as to professional status and pecuniary comfortand we will not deny that it is a vast help to him towards success in life, - it is far different with his hospital brother in London. The hospital doctor in London may derive a certain position from his hospital appointment, but no greater delusion exists than that it is the means of bringing him professional income. I doubt if the profession has the shadow of a notion as to the pecuniary difficulties which beset many a hospital doctor in London. Doomed for years, it may be, to the monotony of out-patient practice, by which he is supposed to be qualifying himself for the treatment of in-patients in the remote future, and, so far, too inexperienced for consulting work, forbidden by custom to earn a living by general practice, and compelled to have a respectable house in a respectable quarter-Harley-street or Brook-street, for example-that he may look, at any rate, as if he were a prosperous man, it is neither more nor less than the truth that, unless by some lucky chance or other he has an independent income to maintain himself, has a lucrative appointment, or a wife with a dowry, has property of his own, or enjoys an allowance from his parents, he has to pass the best years of his life-perhaps his whole lifeoppressed by the load of pecuniary want. The public has little idea that the doctors alone of the staffs of the hospitals 
do their work without remuneration or reward, and general practitioners are many of them so slow to seek or encourage consultative advice that true consultations are extremely rare. Hence it happens that, with a few solitary exceptions, the men who thrive pecuniarily and are satisfied are those who know best how to appeal to the public, and who best cultivate the art of advertising themselves, even though it be at the risk of some distrust on the part of their own brethren. The profession does not hear much of this side of hospital doctors' lives in London, for where is the man who will openly tell you that he is not getting on, or who will boldly admit that he has not taken a single fee for many months? Could the truth be told, the profession would stand amazed at the insignificance of the purely professional incomes of hospital doctors here in London, and at the utter inadequacy of their incomes, even for the bare neesssaries of life. Cutting sections and showing fragments of your departed patients at the Pathological Society may do much for scientific progress: neither pastime does much for bringing in the means of living. When, therefore, Dr. Paget Thurstan and otbers write and speak of a system which makes the bospital doctor and breaks his less fortunate brethren, they do so in ignorance of the real pecuniary condition of one important branch of the profession, the socalled pure consultants in London, supposed to be ever flourishing on the plethora of their guinea or two guinea fees. No, it is not the hospital doctors who break the general practitioner; and if tbe general practitioner desires to raise his income, let him look for and find the means of improving it nearer home. If combination be necessary towards tbis end, by all means combine; but, above all, do away with the practice of underselling each other, which cannot be otherwise than harmful to the whole profession. Let it not be forgotten, moreover, that the system of hard work and no pay which prevails in this rich metropolis amnngst hospital doctors demands as much reform as the sistem of "hard work and poor pay" against which Dr. Paget Thurstan has raised his voice. "Consultants," he saye, "are to family doctors almost precisely as barristers are to solicitors." There is much aptitude in this comparison. The briefless barristers who swarm in the law courts have their exact counterpart in the feeless consultants who herd together and who look so cheery and contented in the regions round about, Cavendish-square.

$$
\text { I am, Sirs, yours truly, }
$$

June 15th, 1887.

$$
\text { A Hospital Surgeon. }
$$

\section{To the Editors of THE LANCET.}

Sins,-Dr. Paget Thurstan has sent you a letter, very valuable in pointing out some great abuses, but ending in so miserable and hopeless a manner that it becomes simply a jeremiad. To me the very blackness of the present condition of general practice is the most hopeful of signs. It is always darkest just before the duwn, and it is the monstrous nature of the abuses to which we are subject which will infuse energy and method into the amœboid mass of general practitioners, and show that they have both brains and mouths, not to mention pens. The most powerful agent at our command is the press, and I believe we shall always find the medical journals more especially willing to aid us in gaining proper respect for the position and remuneration for the services of the medical practitioner. We must have combination. Cela va sans dire. We do not require a trades' union which shall fetter individual discretion, but combination to protect us from the encroachment of gratuitous treatment and the contract system as applied to people able to pay ordinary fees. That is the question in a nutshell. Hospitals, clubs (including friendly societies' associations), and dispensaries, free or provident, must be regulated in the interests both of the general public and the profession. The Council and Corporations will do for us absolutely nothing unless by means of pressure from without. Like Coriolanus, "alone we must do it," but "alone" for us means an army of over 10,000 . We want leaders in this reform, and you, Sirs, with your influential organ, which can both form and lead the opinion of the profession, ought to be our leaders. Free us from the nightmare of the clubs and hospitals, and we can protect oureelves. Dr. Thurstan says the upper and middle clasees pay fairly. Some of them do-some of them are club patients. It ought not to be possible that they can obtain medical advice for a shilling a quarter.

The chief requisite reforms seem to $b_{\theta}:-1$. That admis- sion committees shall investigate the circumstances of all patients recelving gratuitous advice, or semi-gratuitous advice, by means of provident dispensaries, clubs, and friendly societies' associations. 2. That a certain scale shall be fixed from time to time to guide these committees in the exercise of their duties. 3. That amongst the working-classes the ready-money system should be encouraged by a system of small fees. 4. That provident dispensaries should be instituted over the whole country by a national movement for the poor of the working class. 5 . That for parish appointments some uniform system of payment should bo provided.

I cannot agree with Dr. Thurstan as to payment by shilling fees for paupers. It would involve a heavy burden upon the ratepayers in populous districts. Parish patients are (or ought to be) destitute, as far as means of prosuring medical advice is concerned; and if it be necessary to provide for the class above them by provident dispensaries, it would be palpably unfair to tax the local rates with fees for their attendance which would be in excess of the average obtained from the provident patients.

If the above five reforms were insisted on, the medical profession would become more honourable and unselfish in its internal dealings, as well as in its relation to the public. The LANCET has the power of passing these or similar measures by bringing the subject persistently and repeatedly before the profession and the public, and to THE LANCEI I trust chiefly to accomplish this very desirable result.

$$
\begin{gathered}
\text { I am, Sirs, yours truly, } \\
\text { J. B. PIKE, } \\
\text { May 23rd, 188\%. } \\
\text { Med. Officer. Lou ghborough District } \\
\text { and Workhouse. }
\end{gathered}
$$

\section{REFERENCE CASES UNDER THE SALE OF} FOOD ACT.

\section{To the Editors of THE LANCET.}

SrRs,-Suppose a man to be accused of rape, and the medical examination of the woman to have been made promptly. Suppose in the course of some weeks the case to have come before the court, and the medical man who made the examination to state his decided opinion that a rape had been committed. Then suppose some doubt to be raised as to the accuracy of his opinion, and that the court in consequence order an examination of the woman by some higher authority. Suppose the referee were subsequently to come into court and state that he "could not affirm that the rape had been committed," and declined to give any further explanation. Would not the whole of the medical profession be up in arms against such evidence as one-sided, and calculated to frustrate the ends of justice? Why could not the referee state that, owing to the length of time which had elapsed since the crime was alleged to have been committed, his examination was worthless for the intended purpose, and that he could not form an opinion worth having, either one way or the other?

Now I will ask you in the light of this parable to read the following condensation of the complaint formulated in $m y$ letter to the St. James's Gazette, on which you comment in an article in THE LANCET of the 1ith inst.

The Somerset House chemists who are appointed referees under the Act are placed in a very disagreeable and invidious position. Thus they are required to certify whether the condemnation of a sample by a public analyst was correct, when it very frequently happens that they are not in a position to certify either one way or the other; but instead of stating this, the wording of their certificates has commonly been that they were "unable to affrm that the sample in question was adulterated," thus leaving the magistrates to imagine that they affirmed it to be unadulterated, whereas the fact has been that from decomposition or other circumstances they could form no positive opinion on the matter. That this is frequently the case is evident from the fact that it has often been five or six weeks before the sample in dispute has reached their hands. Naturally, under such circumstances, no reliable analysis of the milk has been possible, and although the referees have attempted to avoid the difficulty by making an allowance for change in the milk according to the number of days it has been kept, it is evident that without a knowledge of the circumstances and temperature under which it has been preserved any such corrections are of a wholly worthless character. I may point out also, with every 